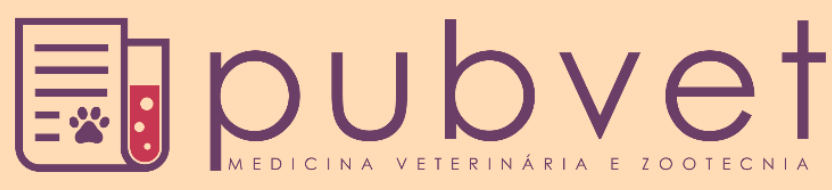

https://doi.org/10.31533/pubvet.v12n12a235.1-6

\title{
Digestibilidade de dietas de ovinos com mistura múltipla a base de raspa integral da mandioca em substituição ao milho
}

\author{
Gláucia Barbosa Coelho ${ }^{1}$, Camila Santos Queiroz ${ }^{2}$, Leandro Macedo Miranda ${ }^{1}$, Alessandra
} Lima Rocha ${ }^{5}$, Antônio Felipe de Sousa Júnior ${ }^{3}$, Isabella Chaves Sousa ${ }^{4}$, Rudson Almeida de Oliveira ${ }^{\circ}$, Nathálya dos Santos Martins ${ }^{5 *}$, Maria Inez Fernandes Carneiro ${ }^{5}$

${ }^{I}$ Mestranda no Programa de Pós-graduação em Defesa Sanitária Animal e Ciência Animal, São Luís, Maranhão, Brasil.

${ }^{2}$ Médica veterinária, São Luís, Maranhão, Brasil.

${ }^{3}$ Discente do curso de Zootecnia - Instituto de ensino superior múltiplo, Tuntun, Maranhão, Brasil.

${ }^{4}$ Doutoranda pela Rede Nordeste em Biotecnologia - UFMA São Luís, Maranhão, Brasil.

${ }^{5}$ Professor (a) da Universidade Estadual do Maranhão, São Luís, Maranhão, Brasil.

* Autor para correspondência, veterinariamartins@hotmail.com

\begin{abstract}
RESUMO. A máxima exploração da capacidade produtiva é possível através da adoção de alternativas alimentares que possibilitem o melhor aproveitamento das forragens a um menor custo. A digestibilidade aparente de dietas com mistura múltipla a base de raspa integral da mandioca em substituição ao milho foi avaliada utilizando-se cinco ovinos da raça Santa Inês, machos, castrados, com idade entre quatro e cinco meses, alojados em gaiolas individuais. Após adaptação, foram realizados cinco períodos experimentais de 15 dias, totalizando 75 dias. A dieta foi composta por feno de Tifton (cynodon spp) e misturas múltiplas com níveis de inclusão de raspa integral de mandioca em substituição ao milho, de acordo com os tratamentos: Sal Mineral (SM), 0\% (MM1), 33\%(MM2), 66\%(MM3) e 100\%(MM4). Foram realizadas coletas de excretas para análise da composição química. Foram avaliados os parâmetros de digestibilidade da matéria seca (DMS\%), proteína bruta (DPB\%) e da fibra em detergente neutro (DFDN\%). Não houve diferença significativa $(\mathrm{p}>0,05)$ na digestibilidade da matéria seca e proteína. Os tratamentos T3 e T4 apresentaram significativamente $(\mathrm{p}<0,05)$ os melhores coeficientes de digestibilidade do FDN. Pode-se recomendar elevados níveis de substituição do milho pela raspa integral de mandioca em dietas para ovinos, estando a escolha em função do custo e disponibilidade local.
\end{abstract}

Palavras chave: Mandioca, ovino, mistura múltipla, digestibilidade

\section{Digestibility of diets of sheep with multiple mixes based on whole grains of manioc in substitution of corn}

ABSTRACT. The maximum exploitation of the productive capacity is possible through the adoption of food alternatives that allow the best use of the fodder at a lower cost. The apparent digestibility of sheep diets kept with multiple mix based on whole manioc scrap in place of maize was evaluated using five castrated Santa Inês male sheep, aged between four and five months, housed in individual cages. After adaptation, five experimental periods of 15 days were performed, totaling 75 days. The diet was composed of Tifton hay (cynodon spp) and multiple mixtures with inclusion levels of whole manioc scrap in place of maize, according to the treatments: Mineral Salt (SM), 0\% (MM1), 33\% (MM2), 66\% (MM3) and 100\% (MM4). Excreta samples were collected to analyze the chemical composition. The digestibility parameters of the dry matter (DMS\%), crude protein (DPB\%) and neutral detergent fiber (DFDN\%) were evaluated. There was no significant 
difference $(p>0.05)$ in dry matter and protein digestibility. The treatments T3 and T4 presented significantly $(\mathrm{p}<0.05)$ the best digestibility coefficients of the NDF. It is possible to recommend high levels of substitution of corn for whole-grain cassava in diets for sheep, being the choice based on cost and local availability.

Key words: Cassava, sheep, multiple mixture, digestibility

\section{Digestibilidad de las dietas de ovino con mezcla múltiple a base de raspa integral de la mandioca en sustitución del maíz}

RESUMEN. La máxima explotación de la capacidad productiva es posible a través de la adopción de alternativas alimentarias que posibiliten el mejor aprovechamiento de los forrajes a un menor costo. La digestibilidad aparente de dietas de ovinos mantenidos con mezcla múltiple a base de la raspa integral de yuca en sustitución al maíz fue evaluada utilizando cinco ovinos de la raza Santa Inés, machos castrados, con edad entre cuatro y cinco meses, alojados en box individuales. Después de la adaptación, se realizaron cinco períodos experimentales de 15 días, totalizando 75 días. La dieta fue compuesta por heno de Tifton (cynodon spp) y mezclas múltiples con niveles de inclusión de raspa integral de yuca en sustitución al maíz, de acuerdo con los tratamientos: Sal Mineral (SM), 0\% (MM1), $33 \%$ (MM1) MM2), 66\% (MM3) y 100\% (MM4). Se realizaron colectas de excretas para el análisis de la composición química. Se evaluaron los parámetros de digestibilidad de la materia seca (DMS\%), proteína bruta (DPB\%) y de la fibra en detergente neutro (DFDN\%). No hubo diferencia significativa ( $p>0,05)$ en la digestibilidad de la materia seca y proteína. Los tratamientos T3 y T4 presentaron significativamente $(\mathrm{p}<0,05)$ los mejores coeficientes de digestibilidad del FDN. Se puede recomendar altos niveles de sustitución del maíz por la raspa integral de mandioca en dietas para ovinos, estando la elección en función de costo y disponibilidad local.

Palabras clave: yuca, ovino, mezcla múltiple, digestibilidad

\section{Introdução}

A ovinocultura apresenta resultados incompatíveis com a potencialidade econômica e a importância social da atividade. Isto decorre da insuficiente disponibilidade de nutrientes nas forragens em certas épocas, conjuntamente com o desconhecimento técnico científico da utilização das alternativas alimentares (Viana 2008; Aquino et al. 2016).

A alimentação constitui-se o custo mais elevado na produção animal (cerca de $70 \%$ ), e este fato aliado a uma baixa disponibilidade e qualidade da pastagem, contribuem diretamente para um menor desempenho produtivo na ovinocultura. Portanto, para que ocorra a máxima exploração da capacidade produtiva é necessária a adoção de alternativas alimentares que possibilitem a um menor custo, o melhor aproveitamento das forragens, principalmente em épocas secas (Aquino et al. 2016). No período seco do ano, as forragens apresentam baixo valor nutritivo não suprindo as exigências em proteína degradada no rúmen (PDR) para crescimento microbiano e atividade fermentativa adequada (Berchielli et al. 2011). A suplementação proteica tem por objetivo oferecer nitrogênio para o crescimento microbiano, visando melhorar a eficiência de síntese de proteína microbiana e fornecer proteína verdadeira para o metabolismo animal (Berchielli et al. 2011).

Os carboidratos são as principais fontes energéticas para o desenvolvimento dos microrganismos do rúmen, e a taxa de produção microbiana pode ser modificada, sensivelmente quando se utilizam diferentes fontes de energia (Caldas Neto 2004; Dias et al. 2008).

A mistura múltipla, resultado da associação de alimentos foi descrita como estratégia para melhorar o aproveitamento de volumosos de baixa qualidade (Ospina \& Ceballos 2002; Prado 2010). Esta pode ser elaborada com fontes alternativas regionais que sejam mais baratas, de bom valor nutritivo e fácil aquisição como, por exemplo, coprodutos da mandioca (Caldas Neto et al. 2000; Jorge et al. 2002; Zeoula et al. 2002; Abrahão \& Prado 2004).

A mandioca manihot esculenta Crantz é uma planta originária do nordeste brasileiro, cultivada antes mesmo da colonização (Conceição 1987). O Brasil está entre os maiores produtores de mandioca do mundo (Souza \& Fialho 2003; Silva et al. 2009). 
Pela dificuldade em se quantificar a digestibilidade real, adota-se a digestibilidade aparente como parâmetro de valor nutritivo, obtida pela diferença entre a quantidade de alimento ou nutrientes ingeridos e a excreção fecal, influenciada diretamente pelo tempo de permanência do alimento no trato gastrintestinal (Dian et al. 2008; Berchielli et al. 2011). Portanto, a digestibilidade aparente e o consumo do alimento são importantes parâmetros utilizados na pesquisa animal para desenvolver adequados sistemas de alimentação (Van Soest 1994). A estimativa da digestibilidade aparente do alimento, principalmente da proteína e da energia é utilizada para avaliação de dietas para ruminantes, indicando o potencial de aproveitamento dos ruminantes. Dentre as técnicas, dá-se destaque a digestibilidade in vivo, por produzir resultados reais quando comparado ao método in vitro (Sampaio 1994).

A avaliação de ingredientes regionais que possam substituir total ou parcialmente alimentos convencionais e/ou combinarem a outros de diferentes características digestivas justifica-se pela necessidade de formulação de dietas viáveis economicamente (Martins et al. 2000; Medroni et al. 2000; Ramalho et al. 2006). Os resultados dos ensaios para a avaliação do consumo e digestibilidade dos alimentos para ruminante são importantes para a formulação eficientes e de menor custo (Conceição et al. 2009).

O objetivo deste trabalho foi avaliar a digestibilidade aparente, in vivo de dietas contendo mistura múltipla com $0 \%, 33 \%, 77 \%$ e $100 \%$ com substituição de milho pela raspa integral de mandioca em ovinos.

\section{Material e métodos}

O estudo foi realizado no setor de caprinoovinocultura do Centro de Ciências Agrárias, Departamento de Zootecnia, Universidade Estadual do Maranhão, localizada no município de
São Luís. Foram utilizados cinco ovinos da raça Santa Inês, machos, castrados, com idade entre quatro e cinco meses e peso vivo médio de $20 \mathrm{~kg}$. Após a pesagem e identificação, os animais foram vermifugados e alojados em gaiolas individuais de piso ripado, equipada com cocho para fornecimento de volumoso, saleiro para fornecimento de mistura múltipla, e bebedouros com água permanente e a disposição.

Após período de 30 dias de adaptação às instalações e dietas, deu-se início às coletas. Foram realizados cinco períodos experimentais, cada um com 15 dias, sendo 10 dias de adaptação e 5 dias de coleta, totalizando 75 dias.

A composição química da dieta encontra-se na tabela $1 . O$ volumoso utilizado foi o feno de Tifton (cynodon spp), produzido na Fazenda Cristal, localizada no município de Vargem Grande, estado do Maranhão. O Capim após passar pelo processo de fenação foi triturado em máquina adequada e armazenado em sacos de náilon para facilitar o armazenamento. $\mathrm{O}$ farelo de soja foi utilizado como fonte de proteína verdadeira e a ureia como fonte de nitrogênio não proteico.

A raspa integral de mandioca é constituída pela polpa e pela casca da raiz, que depois de triturada e seca ao sol, passou por um processo de trituração em máquina forrageira para posterior confecção das misturas múltiplas.

As misturas múltiplas foram elaboradas utilizando-se milho moído, farelo de soja, raiz integral de mandioca, ureia, sal comum e suplemento mineral (SM), misturadas manualmente. As dietas foram formuladas conforme recomendação do NRC (2007) para atender as exigências de ovinos em crescimento com peso vivo médio de $20 \mathrm{~kg}$. Os níveis de inclusão da raspa integral de mandioca em substituição ao milho moído nas misturas múltiplas foram: Sal Mineral (SM), 0\% (MM1), $33 \%$ (MM2), 66\% (MM3) e 100\% (MM4), como se pode observar na tabela 2.

Tabela 1. Composição química dos alimentos e das misturas múltiplas, na base da matéria seca.

\begin{tabular}{|c|c|c|c|c|c|c|c|}
\hline & & \multicolumn{5}{|c|}{ Nutrientes (\%) } & \multirow[b]{2}{*}{ CINZAS } \\
\hline & & MS & PB & $\mathrm{EE}$ & FB & FDN & \\
\hline \multirow{4}{*}{$\underline{\text { Alimentos }}$} & Fubá de milho & 88,80 & 8,16 & 3,05 & 1,20 & 10,82 & 1,5 \\
\hline & Farelo de soja & 89,30 & 43,16 & 2,20 & 3,50 & 12,92 & 6,73 \\
\hline & Raspa de mandioca & 88,10 & 3,93 & 1,60 & 3,70 & 13,64 & 4,23 \\
\hline & Feno de Tifton & 89,20 & 9,47 & & - & 73,40 & 7,1 \\
\hline \multirow{4}{*}{$\underline{\text { Misturas Múltiplas }}$} & MM1 & 90,30 & 59,13 & 2,25 & 1,90 & 8,80 & 40,7 \\
\hline & MM2 & 86,50 & 57,06 & 1,15 & 1,10 & 10,15 & 37,86 \\
\hline & MM3 & 89,20 & 57,86 & 1,45 & 1,65 & 12,35 & 37,63 \\
\hline & MM4 & 90,7 & 54,68 & 1,95 & 2,15 & 12,95 & 40,16 \\
\hline
\end{tabular}

LNA/DZ/CCA/UEMA 
Tabela 2. Proporção dos ingredientes nas misturas múltiplas e suplemento mineral (\%).

\begin{tabular}{lccccc}
\hline & SM & MM1 & MM2 & MM3 & MM4 \\
\hline Farelo de Soja (\%) & - & 22,00 & 20,00 & 20,00 & 20,00 \\
Uréia + Enxofre (\%) & - & 18,00 & 20,00 & 20,00 & 20,00 \\
Fubá de Milho (\%) & - & 20,00 & 13,20 & 6,80 & - \\
Raspa Integral Mandioca (\%) & - & - & 6,80 & 13,20 & 20,00 \\
Sal Comum (\%) & 50,00 & 20,00 & 20,00 & 20,00 & 20,00 \\
Sal Mineral - SM (\%) & 50,00 & 20,00 & 20,00 & 20,00 & 20,00 \\
Total & 100,00 & 100,00 & 100,00 & 100,00 & 100,00 \\
\hline
\end{tabular}

Durante o experimento, foram oferecidos aos animais, água a disposição, volumoso uma vez ao dia, sempre as 8:00 h e a mistura múltipla correspondente ao tratamento. Estes foram sequenciados de forma aleatória como pode ser observado no quadro 1.

Quadro 1. Sequência dos tratamentos, onde $\mathrm{A}=\mathrm{T} 0(\mathrm{SM}) ; \mathrm{B}=$ T1(MM1); C = T2 (MM2); D= T3 (MM3) e E = T4 (MM4).

\begin{tabular}{lccccc}
\hline Tratamentos & \multicolumn{5}{c}{ Animais } \\
\cline { 2 - 6 } & 1 & 2 & 3 & 4 & 5 \\
\hline T1 & B & C & D & A & E \\
T2 & E & A & B & C & D \\
T3 & D & B & C & E & A \\
T4 & A & D & E & B & C \\
T5 & C & E & A & D & B \\
\hline
\end{tabular}

O delineamento estatístico adotado foi do tipo change-over, com um quadrado latino ( $5 \times 5$ ) (Cochran \& Cox 1957). O esquema de análise de variância para o delineamento encontra-se na tabela 3. Eram fornecidos aos animais diariamente, $100 \mathrm{~g}$ de mistura múltipla. As sobras do feno foram pesadas diariamente, com o objetivo de determinar o consumo médio diário de volumoso, e no final de cada tratamento as sobras das misturas também foram pesadas.

Tabela 3. Esquema da análise de variância

\begin{tabular}{lc}
\hline Fontes de variação & Graus de liberdade \\
\hline Tratamentos & 4 \\
Animais dentro do grupo & 4 \\
Períodos dentro do grupo & 4 \\
Resíduos & 12 \\
\hline Total & 24
\end{tabular}

As médias foram comparadas pelo teste de Tukey (Cochran \& Cox 1957), considerando-se o nível de significância de 5\%.

As coletas das fezes foram realizadas diariamente às 8:00 horas. Bolsas coletoras adaptadas aos animais foram utilizadas. Após a homogeneização, uma amostra de $10 \%$ era retirada e armazenada em sacos plásticos, individuais, e congelada a $-10^{\circ} \mathrm{C}$, para posterior análise.
As análises das fezes foram realizadas no Laboratório de Nutrição Animal, do Departamento de Zootecnia/CCA/UEMA. Estas, após secagem em estufa de ar forçado a $55^{\circ} \mathrm{C}$ por 72 horas, eram moídas em peneiras de $1 \mathrm{~mm}$, para posterior analise da matéria seca (MS), proteína bruta (PB) e matéria mineral (MM) de acordo com Detmann et al. (2012).

Foram analisados os parâmetros de digestibilidade da matéria seca (DMS\%), proteína bruta (DPB\%) e matéria mineral (DMM\%), extrato etéreo (DEE\%). Os coeficientes de digestibilidade (CD\%) foram calculados pela fórmula fornecida por Silva \& Leão (1979).

( $\mathrm{kg}$ de nutrientes ingeridos $-\mathrm{kg}$

$$
\mathrm{CD} \%=\frac{\text { de nutrientes excretados) }}{\text { kg de nutrientes ingerido }} \times 100
$$

\section{Resultados e discussão}

A tabela 4 apresenta os resultados da MS, PB e FDN encontrados na análise das excretas de animais recebendo misturas múltiplas com a inclusão de mandioca em substituição ao milho. Os resultados da digestibilidade aparente da matéria seca, proteína bruta e fibra em detergente neutro dos tratamentos encontram-se na tabela 5.

Tabela 4. Composição química das excretas de ovinos mantidos com feno de tifton e suplementados com misturas múltiplas com diferentes níveis de inclusão de mandioca.

\begin{tabular}{lccccc}
\hline Composição & \multicolumn{5}{c}{ Tratamentos* } \\
\cline { 2 - 6 } $\begin{array}{l}\text { química das } \\
\text { excretas (\%) }\end{array}$ & T0 & T1 & T2 & T3 & T4 \\
\hline MS & 31,58 & 35,67 & 33,48 & 33,44 & 33,60 \\
PB & 8,44 & 20,65 & 22,41 & 21,30 & 20,26 \\
FDN & 64,79 & 66,86 & 66,45 & 66,37 & 66,51 \\
\hline
\end{tabular}

*T0 = SM; T1 = MM1; T2 = MM2; T3= MM3; T4 = MM4

Não houve diferença $(\mathrm{P}>0,05)$ na digestibilidade da matéria seca entre os tratamentos com diferentes níveis de substituição do milho pela mandioca. 
Tabela 5. Coeficientes de digestibilidade da matéria seca (CDMS) e da proteína bruta (CDPB), da fibra detergente neutro (CDFDN) de dietas para ovinos mantidos com feno de tifton e suplementados com misturas múltiplas com diferentes níveis de inclusão de mandioca. Digestibilidade, $\%$ Tratamentos*

\begin{tabular}{lcccccc}
\cline { 2 - 7 } & T0 & T1 & T2 & T3 & T4 & CV, \% \\
\hline CDMS & $51,59 \mathrm{~b}$ & $60,49^{\mathrm{a}}$ & $58,29 \mathrm{a}$ & $62,95 \mathrm{a}$ & $62,05 \mathrm{a}$ & 5,42 \\
CDPB & $10,87 \mathrm{~b}$ & $65,07^{\mathrm{a}}$ & $60,78 \mathrm{a}$ & $63,18 \mathrm{a}$ & $62,94 \mathrm{a}$ & 7,15 \\
CDFDN & $28,79 \mathrm{~b}$ & $33,14 \mathrm{~b}$ & $33,55 \mathrm{~b}$ & $41,63 \mathrm{a}$ & $39,49 \mathrm{a}$ & 4,85 \\
\hline
\end{tabular}

Letras diferentes na mesma linha diferem estatisticamente $(\mathrm{p}<5 \%) . * \mathrm{~T} 0=\mathrm{SM} ; \mathrm{T} 1$ = MM1; T2 = MM2; T3= MM3; T4 = MM4.

Apenas o tratamento T0 - mistura mineral, diferiu estatisticamente $(\mathrm{P}<0,05)$ dos demais tratamentos à base de mistura múltipla. Ramalho et al. (2006) também não observaram diferenças utilizando raspa de mandioca em substituição ao milho para vacas em lactação.

A digestibilidade da MS da mandioca e de seus subprodutos, em geral, é semelhante às do milho (Caldas Neto et al. 2000; Zeoula et al. 2003). Martins et al. (2000) obtiveram maior digestibilidade da matéria seca com dietas contendo raspa de mandioca quando comparadas as dietas contendo milho como fonte de energia. Para Zeoula et al. (1999) o amido de mandioca apresenta maior potencial de degradação no rumem que o amido de milho. Evidência também verificada por Jorge et al. (2002).

$\mathrm{O}$ coeficiente de digestibilidade da proteína bruta (CDP) foi significativamente maior $(\mathrm{P}<$ $0,05)$ nos tratamentos com uso de misturas múltiplas, não diferindo entre si quanto ao nível de substituição do milho pela mandioca. Prado et al. (1999) encontraram CDPB de $66,4 \%$ para misturas múltiplas contendo mandioca como fonte de energia. Martins et al. (2000) observaram valor médio de digestibilidade da PB de 53,9\% inferior a 63,6\% encontrado por Medroni et al. (1999).

Os tratamentos T3 e $\mathrm{T} 4$ apresentaram significativamente $(\mathrm{P}<0,05)$ os melhores coeficientes de digestibilidade do FDN; para os tratamentos T0, T1 e T2 não houve diferença significativa entre si, apresentando os menores coeficientes de digestibilidade. Conceição et al. (2009) também não verificaram efeito significativo quanto da inclusão de raspa integral de mandioca sobre a digestibilidade do FDN em dietas para ovinos confinados. Zeoula et al. (2003) obtiveram coeficientes de digestibilidade do FDN de $53,9 \%$ para ovinos mantidos com dieta, quando da substituição do milho pela farinha de mandioca.

\section{Conclusão}

A substituição do milho pela raspa integral de mandioca não alterou os coeficientes de digestibilidade da matéria seca e proteína bruta, nos diferentes tratamentos. Os níveis de substituição de 66 e $100 \%$ de milho por raspa integral de mandioca promoveram maiores coeficientes de digestibilidade da fibra em detergente neutro. Portanto, pode-se recomendar elevados níveis de substituição do milho pela raspa integral de mandioca em dietas para ovinos, estando à escolha em função de custo e disponibilidade local.

\section{Referências Bibliográficas}

Abrahão J.J.S. \& Prado I.N. 2004. Subprodutos da mandioca na alimentação para produção de carne e leite em ruminantes. In: Conceitos sobre a produção com qualidade de carne e leite (ed. by Prado IN), pp. 147-164. Eduem, Maringá, Paraná, Brasil.

Aquino R.S., Lemos C.G., Alencar C.A., Silva E.G., Silva Lima R., Gomes J.A.F. \& Silva A.F. 2016. A realidade da caprinocultura e ovinocultura no semiárido brasileiro: um retrato do sertão do Araripe, Pernambuco. PUBVET 10, 271-281.

Berchielli T.T., Pires A.V. \& Oliveira S.G. 2011. Nutrição de Ruminantes. FUNEP, Jaboticabal, Brazil.

Caldas Neto S.F. 2004. Metabolismo do amido em ruminantes. In: Conceitos sobre a produção com qualidade de carne e leite (ed. by Prado IN), pp. 81-114. Eduem, Maringá, Paraná, Brasil.

Caldas Neto S.F., Zeoula L.M., Branco A.F., Prado I.N., Santos G.T., Fregadolli F.L., Kassies M.P. \& Dalponte A.O. 2000. Mandioca e resíduos das farinheiras na alimentação de ruminantes: digestibilidade total e parcial. Revista Brasileira de Zootecnia 29, 2099-2108.

Cochran W. \& Cox G.M. 1957. Experimetal Desing. New York: John Wiley and Sons, 1957, 611p. John Wiley and SonS, New York, USA.

Conceição A.J. 1987. A mandioca.

Conceição W.L.F., Figueirêdo A.V., Nascimento H.T.S., Vasconcelos V.R., Alves A.A. \& Dantas Filho L.A. 2009. Valor nutritivo de dietas contendo raspa integral da mandioca para ovinos 
confinados. Acta Scientiarum. Animal Sciences 31, 397-402.

Detmann E., Souza M., Valadares Filho S., Queiroz A., Berchielli T., Saliba E., Cabral L.S., Pina D.S., Ladeira M. \& Azevedo J. 2012. Métodos para análise de alimentos. Suprema, Minas Gerais.

Dian P.H.M., Prado I.N., Geron L.J.V., Lobo Júnior A.R., Zeoula L.M., Scomparin V.X. \& Moreira F.B. 2008. Apparent digestibility and in situ degradability of diets with cassa by-products fed to beef bulls. Archivos de Zootecnia 57, 373-376.

Dias A.M., Silva F.F., Veloso C.M., Ítavo L.C.V., Pires A.J.V., Damasceno J.C., Souza D.R., Sá J.F., Nascimento P.V.N. \& Machado E.F. 2008. Digestibilidade dos nutrientes do bagaço de mandioca em dietas de novilhas leiteiras. Arquivo Brasileiro de Medicina Veterinária e Zootecnia 60, 996-1003.

Jorge J.R.V., Zeoula L.M., Prado I.N. \& Geron L.J.V. 2002. Substituição do milho pela farinha de varredura (Manihot esculenta, Crantz) na ração de bezerros holandeses. 2. Digestibilidade e valor energético. Revista Brasileira de Zootecnia 31, 205-212.

Martins A.S., Prado I.N., Zeoula L.M., Branco A.F. \& Nascimento W.G. 2000. Apparent digestibility of diets containing corn or cassava hull as energy source and cottonseed meal or yeast as protein source, in heifers. Revista Brasileira de Zootecnia 29, 269-277.

Medroni S., Prado I.N., Nascimento W.G., Vinocur K., Iwayama P.T. \& Matsushita M. 2000. Efeito da combinação de dietas contendo milho ou triticale e farelo de soja ou levedura sobre o desempenho de novilhas nelore terminadas em confinamento. Acta Scientiarum. Animal Sciences 22, 787-791.

Medroni S., Prado I.N., Zeoula L.M. \& Nascimento W.G. 1999. Digestibilidade in vivo de dietas contendo milho ou triticale e farelo de soja ou levedura em novilhas nelore em confinamento. Acta Scientiarum. Animal Sciences 21, 645-649.

NRC 2007. Nutrient requirements of small ruminants: sheep, goats, cervids, and new world camelids. Natl. Acad. Press, Washington, DC., Washington.

Ospina B. \& Ceballos H. 2002. La yuca en el tercer milenio: sistemas modernos de producción, procesamiento, utilización y comercialización. CIAT.

Prado I.N. 2010. Produção de bovinos de corte e qualidade da carne. Eduem, Maringá, Paraná, Brasil.

Prado I.N., Marques J.A., Branco A.F., Zeoula L.M. \& Caldas Neto S.F. 1999. Avaliação da substituição do milho pela mandioca e seus resíduos na digestibilidade aparente em novilhas confinadas. Acta Scientiarum. Animal Sciences 21, 677-682.

Ramalho R.P., Ferreira M.A., Véras A.S.C., Lima L.E. \& Rocha V. 2006. Substituição do milho pela raspa de mandioca em dietas para vacas primíparas em lactação. Revista Brasileira de Zootecnia 35, 1221-1227.

Sampaio I.B.M. 1994. Contribuições estatísticas e de técnica experimental para ensaios de degradabilidade de forragens quando avaliada in situ. In: Reunião Anual da Sociedade Brasileira de Zootecnia, pp. 81-82. Sociedade Brasileira de Zootecnias, Mari gá, Paraná, Brasil.

Silva A., Santana L., França C., Magalhães C., Araíjo C. \& Azevedo S. 2009. Produção de diferentes variedades de mandioca em sistema agroecológico. Revista Brasileira de Engenharia Agricola e Ambiental 13, 33-38.

Silva J. \& Leão M. 1979. Fundamentos de nutrição de ruminantes. Livroceres, Piracicaba.

Souza L.S. \& Fialho J.F. 2003. Cultivo da mandioca para a região do Cerrado. Embrapa Mandioca e Fruticultura 8.

Van Soest P.J. 1994. Nutritional ecology of the ruminant. Cornell University Press, Ithaca, NY, USA.

Viana J.G.A. 2008. Panorama geral da ovinocultura no mundo e no Brasil. Revista Ovinos 4, 1-9.

Zeoula L.M., Caldas Neto S.F., Geron J.L.J., Maeda E.M., Prado I.N., Dian P.H.M., Vieira Jorge J.R. \& Marques J.A. 2003. Cassava by-product flour replacing corn in ration for sheep: intake, digestibility, nitrogen and energy balances and ruminal parameters. Revista Brasileira de Zootecnia 32, 491-502.

Zeoula L.M., Martins A.S., Prado I.N., Alcalde C., Branco A. \& Santos G.T. 1999. Solubilidade e degradabilidade ruminal do amido de diferentes alimentos. Revista Brasileira de Zootecnia 28, 898-905.

Zeoula L.M., Neto S.F.C., Branco A.F., Prado I.N., Dalponte A.O., Kassies M. \& Fregadolli F.L. 2002. Mandioca e resíduos das farinheiras na alimentação de ruminantes: $\mathrm{pH}$, concentração de N-NH. Revista Brasileira de Zootecnia 31, 15821593.

Recebido: 17 outubro, 2018

Aprovado: 12 novembro, 2018

Publicado: 27 dezembro, 2018

Licenciamento: Este artigo é publicado na modalidade Acesso Aberto sob a licença Creative Commons Atribuição 4.0 (CC-BY 4.0), a qual permite uso irrestrito, distribuição, reprodução em qualquer meio, desde que o autor e a fonte sejam devidamente creditados. 